\title{
PHÁT TRIỂN TRẠM THU ẢNH VIỄN THÁM Ở MỘT SỐ NƯỚC ĐÔNG NAM Á - BÀI HỌC KINH NGHIỆM CHO VIẸTT NAM
}

\author{
LÊ MINH SO'N(1), NGÔ DUY TÂN(2) \\ (1)Cục Viễn thám Quốc gia \\ ${ }^{(2)}$ Viện Công nghệ Vũ trụ - Viện Hàn lâm Khoa học và Công nghệ Việt Nam
}

\section{Mở đầu}

Công nghệ vũ trụ là một ngành công nghệ cao, được tích hợp từ nhiều ngành khoa học công nghệ khác nhau nhằm chế tạo và ứng dụng các phương tiện như vệ tinh, tàu vũ trụ, tên lửa đẩy, trạm mặt đất, v.v... để khám phá vũ trụ vì lợi ích con người. Ở các nước phát triển, công nghệ vũ trụ ngày nay được ứng dụng rộng rãi trong phát triển kinh tế, văn hoá, giáo dục, y tế, an ninh, quốc phòng và nhiều ngành khoa học khác.

Ở Việt Nam trong những năm gần đây, nhiều thành tựu của khoa học và công nghệ vũ trụ đã được triển khai ứng dụng, đặc biệt trong các lĩnh vực thông tin liên lạc, khí tượng thủy văn, quan trắc Trái đất. Ngày 14/06/2006, Thủ tướng Chính phủ đã ban hành Quyết định số 137/2006/QĐ/TTg phê duyệt "Chiến lược nghiên cứu và ứng dụng công nghệ vũ trụ của Việt Nam đến năm 2020". Trong chiến lược này, Trạm thu ảnh viễn thám của Việt Nam được xây dựng đáp ứng nhu cầu phát triển công nghệ vũ trụ nói chung và công nghệ viễn thám nói riêng, tiến tới đáp ứng được nhu cầu ứng dụng ảnh viễn thám trong quản lý môi trường và thiên tai.

Trong khu vực Đông Nam Á, một số nước đã chú trọng công nghệ vũ trụ từ rất sớm, mỗi nước định hướng chương trình phát triển và ứng dụng công nghệ vũ trụ cho riêng mình, phù hợp với mục đích, điều kiện và đặc điểm cụ thể. Các nước như Inđônêxia, Thái Lan, Malayxia là những quốc gia phát triển chương trình công nghệ vũ trụ từ những năm 1980 của thế kỷ trước. Nghiên cứu tổng quan các trạm thu ảnh viễn thám ở các nước trong khu vực Đông Nam $A^{\prime}$ cho ta cái nhìn khái quát bức tranh phát triển công nghệ vũ trụ nói chung và trạm thu ảnh viễn thám nói riêng ở trong khu vực, học tập kinh nghiệm của các nước để định hướng phát triển cho Việt Nam.

\section{Phát triển trạm thu ảnh viễn thám ở một số nước điển hình tại Đông Nam Á}

\subsection{Inđônêxia}

1.1.1. Chương trình vệ tinh nhỏ quan sát Trái đất của Inđônêxia

Viện Hàng không và Vũ trụ quốc gia Inđônêxia (LAPAN) là cơ quan trực thuộc chính phủ Indonesia, được thành lập năm 1963, có chức năng nghiên cứu hàng không vũ trụ ứng dụng trong dân sự và quân sự, phát triển vệ tinh nhỏ quan sát Trái đất và vệ tinh viễn thông. Trong quá trình phát triển công nghệ vũ trụ, In đô nê xia lựa chọn cách tiếp cận chương trình công nghệ vũ trụ với chi phí thấp, phát triển vệ tinh nhỏ phục vụ phát triển nhu cầu ứng dụng công nghệ viễn

Ngày nhận bài: 13/9/2016, ngày chuyển phản biện: 15/9/2016, ngày chấp nhận phản biện: 22/9/2016, ngày chấp nhận đăng: 26/9/2016 
thám và các ngành kinh tế khác.

Là quốc gia có lãnh thổ và lãnh hải rộng lớn và đa dạng, Inđônêxia đã triển khai ứng dụng công nghệ vũ trụ để giải quyết các nhu cầu trong các lĩnh vực: Viễn thông (vệ tinh viễn thông của Inđônêxia đã bắt đầu hoạt động từ năm 1976); Quan sát Trái đất; Giảm nhẹ thiên tai; Định vị dẫn đường; Cứu nạn cứu hộ; Y tế; Giáo dục [1].

Năm 2003, Inđônêxia phát triển vệ tinh nhỏ đầu tiên có tên là LAPAN-TUBSAT (LAPAN-A1). Vệ tinh được lắp ghép, tích hợp và thử nghiệm trong thời gian 2004 2005 tại Trường Đại học Công nghệ Berlin Đức. Liên lạc giữa vệ tinh và trạm mặt đất (truyền, phát tín hiệu, dò tìm vệ tinh) sử dụng dải sóng UHF, tín hiệu video chụp ảnh truyền xuống trạm mặt đất thông qua tần số băng S (kỹ thuật analog). Vệ tinh đã phóng thành công năm 2007 và đã kết thúc hoạt động vào năm 2013[1].

Dựa trên những kinh nghiệm đã đạt được từ LAPAN-TUBSAT, Inđônêxia tiếp tục phát triển, phóng và vận hành vệ tinh nhỏ LAPAN-A2. Là vệ tinh có quỹ đạo cận xích đạo, độ cao 650 km, góc nghiêng $8^{\circ}$, chu kỳ vòng quay là 98 phút, quỹ đạo này cho phép liên lạc nhiều lần trong này (14 lần) [2], LAPAN-A3 (6/2016).

\subsubsection{Hệ thống trạm mặt đất}

Hệ thống trạm thu ảnh viễn thám của Inđônêxia bao gồm 5 trạm đặt ở các vị trí khác nhau, do đặc thù lãnh thổ trải rộng qua nhiều kinh tuyến, LAPAN sử dụng một mạng lưới trạm thu để thu nhận tín hiệu của các vệ tinh viễn thám thương mại và để điều khiển và vận hành các vệ tinh nhỏ (LAPANTUBSAT, LAPAN-A2 and LAPAN-A3). Mạng Iưới bao gồm 5 trạm mặt đất: trạm Rumpin và trạm Rancabungur ở tỉnh Bogor, trạm Bukittinggi ở West Sumatra, trạm Pontianak ở West Borneo và trạm Biak ở Papua. Trong mạng lưới trạm mặt đất này, trạm Rumpin là trạm điều khiển chính, trạm Rancabungur là

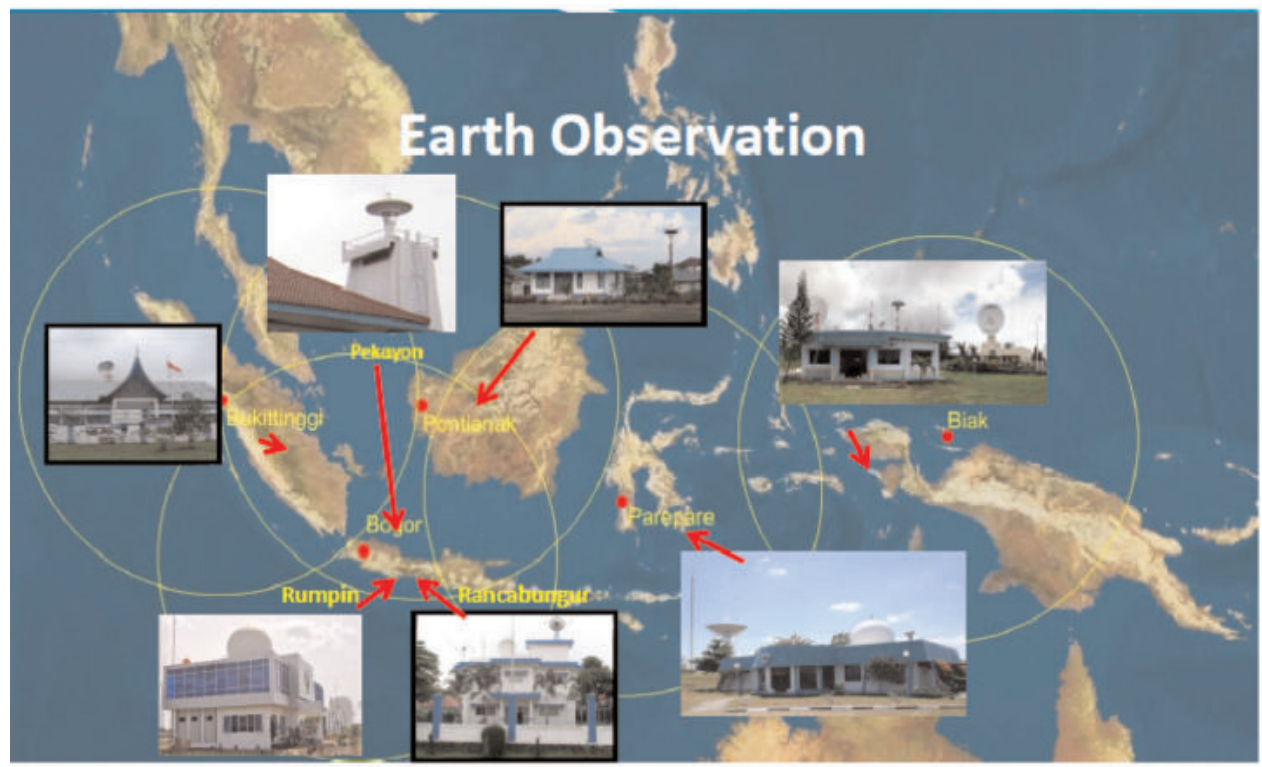

Hình 1: Mạng lưới trạm thu của LAPAN-TUBSAT, LAPAN-A2 and LAPAN-A3 (Nguồn: LAPAN) 
trạm dự phòng cho trạm Rumpin, đảm bảo phủ kín vùng phía Tây của Indonesia. Trạm Bukittinggi thu nhận bao phủ vùng Tây Bắc, gồm cả tỉnh Aceh, trạm Pontianak và Biak phủ vùng miền Trung và phía Đông. Trong tương lai, Inđônêxia dự định xây các trạm ở Pare-pare, Celebes để phủ phần trung tâm của Inđônêxia [3]. (Xem hình 1)

Trạm Rumpin và Biak là trạm mặt đất thu nhận các dữ liệu của vệ tinh thời tiết và là trạm dự phòng cho cả các vệ tinh thời tiết và vệ tinh viễn thám. Trạm Rancabungur dùng để nghiên cứu và dự báo khí tượng. Trạm Pontianak và Bukittinggi là trạm điều khiển và thu nhận các tín hiệu vệ tinh khác.

Dữ liệu viễn thám thu nhận ở 2 trạm chính Parepare và Rumpin gồm: Terra/Aqua MODIS; NPP VIIRS; Landsat-7; SPOT-5 and SPOT-6; Landsat-8. Tram Jakarta thu nhận dữ liệu vệ tinh khí tượng: NOAA-19; Feng Yung-3A; MTSAT-1R [3].

\subsection{Thái Lan}

Cơ quan Phát triển Công nghệ vũ trụ và Địa tin học Thái Lan - GISTDA là một tổ chức nhà nước nghiên cứu và phát triển công nghệ viễn thám và công nghệ vũ trụ. Cung cấp dữ liệu viễn thám và dữ liệu thông tin địa lý cho các cơ quan nhà nước và các tổ chức của Thái Lan.

Năm 2004, Thái Lan phát triển chương trình vệ tinh riêng của và hợp tác với Công ty Hàng không Vũ trụ Châu Âu (EADS) để chế tạo và chuyển giao vệ tinh THEOS (The Thailand Earth Observation Satellite), vệ tinh viễn thám đầu tiên của Thái Lan. Tháng 10/2008, vệ tinh THEOS được phóng thành công lên quỹ đạo, Thái Lan vận hành hệ thống vệ tinh của mình đồng thời cũng thu nhận và xử lý các loại ảnh vệ tinh trước đó mà trạm vẫn thu nhận.

Cơ sở hạ tầng của trạm thu nhận dữ liệu vệ tinh của Thái Lan đã bắt đầu xây dựng từ năm 1982. Ban đầu từ một trạm thu ảnh vệ tinh Landsat, đến nay Thái Lan đã có mạng

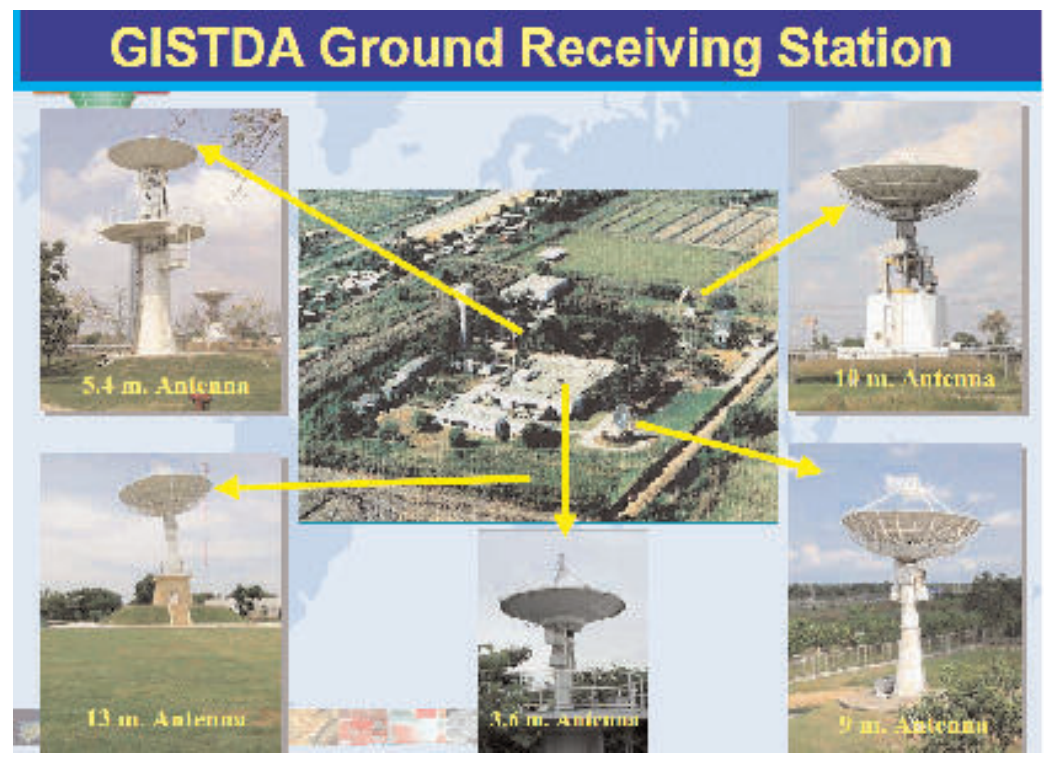

Hình 2: Trạm thu ảnh vệ tinh của Thái Lan tại Lad Krabang, Bangkok (Nguồn: GISTDA) 
lưới trạm thu nhận, xử lý và cung cấp nhiều loại ảnh vệ tinh tương mại của thế giới ở các loại phân giải không gian và phân giải phổ khác nhau (Cosmo-SkyMed, KOMPSAT, LANDSAT-5, RADARSAT-2), phục vụ cho các ứng dụng khác nhau trong nghiên cứu và quản lý tài nguyên và môi trường [4]. (Xem hình 2)

Năm 2003, sân bay quốc tế Suvarnabhumi Airport được xây dựng và đi vào hoạt động, tháp điều khiển không lưu của sân bay này (cao 132m) hoạt động ở tần số sóng radar đã gây nhiễu nặng tới trạm điều khiển vệ tinh và các hoạt động thu nhận tín hiệu vệ tinh. Vì vậy, trạm thu ảnh vệ tinh Thái Lan di chuyển xuống khu tổ hợp Krenovation, Siracha tỉnh Cholburi, phần thu ảnh Theos hiện vẫn còn hoạt động ở đây [5].

\subsection{Malayxia}

Cơ quan Viễn thám Malayxia là tổ chức trực thuộc Bộ Khoa học Công nghệ Malayxia, được thành từ năm 2008 trên cơ sở của Trung tâm Viễn thám Malayxia trước đây (1988). Nhiệm vụ của cơ quan này là ứng dụng công nghệ viễn thám và các công nghệ liên quan để quản lý tài nguyên thiên nhiên, môi trường, thiên tai, an ninh, đất đai và phát triển cơ sở hạ tầng quốc gia.

Đối với phát triển viễn thám, Malayxia chia ra làm 3 mảng hoạt động: Người sử dụng (phát triển ứng dụng và nguồn nhân lực); Trạm mặt đất (thu nhận dữ liệu viễn thám; Vũ trụ (phát triển năng lực chế tạo vệ tinh, phóng và vận hành hệ thống vệ tinh của riêng mình). Ngoài ra, Cơ quan quan Viễn thám Malayxia còn quản lý các trạm thu ảnh vệ tinh viễn thám khác[6].

Về công nghệ vũ trụ, cũng như Indonesia, Malaysia lựa chọn tự phát triển các vệ tinh nhỏ để phục vụ thử nghiệm công nghệ vệ tinh ứng dụng trong viễn thám và thông tin vệ tinh. Các vệ tinh nhỏ do Malaysia hợp tác với các nước phát triển để chế tạo và phóng lên vũ trụ là vệ tinh TiungSAT-1 (9/2000 - 2004), tiếp theo là vệ tinh RazakSAT (7/2009 - 10/2010) [7].

Các trạm thu ảnh viễn thám của Malaysia

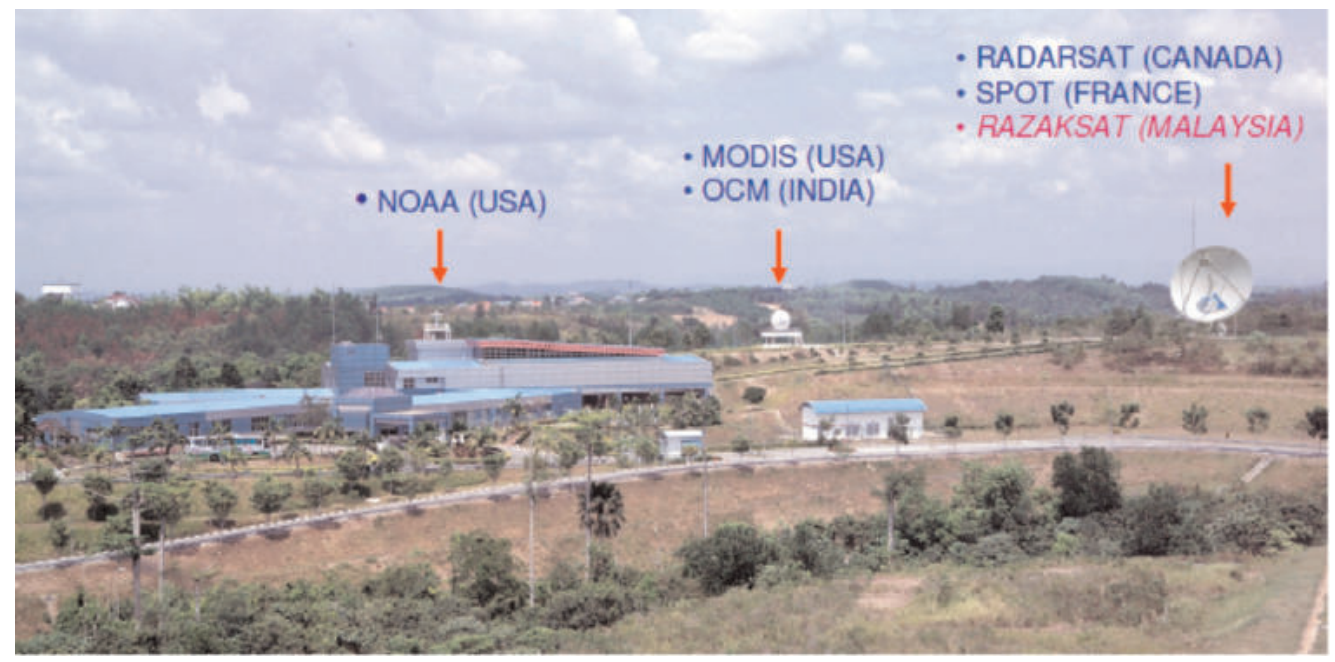

Hình 3: Toàn cảnh trạm thu Malaysia

(Nguồn: Cơ quan Viễn thám Malaysia) 
do Cơ quan Viễn thám quốc gia Malaysia vận hành và quản lý, trạm đặt tại tỉnh Temerloh. Các trạm này thu nhận và xử lý các tín hiệu vệ tinh viễn thám thương mại và vệ tinh khí tượng như Radarsat-1 của Canada, SPOT 2, 4 and 5 của Pháp, IPS-P4 của Ấn Độ, Terra / Aqua và NOAA của Mỹ. (Xem hình 3)

\section{Các trạm thu ảnh vệ tinh hiện tại và tương lai ở Việt Nam}

Ở Việt Nam, trạm thu ảnh vệ tinh bắt đầu được xây dựng từ những năm 70 của thế kỷ trước, chủ yếu thu ảnh mây của vệ tinh khí tượng phục vụ công tác dự báo thời tiết. Trong giai đoạn 1986 - 1988, Tổng cục Khí tượng - Thủy văn đã được trang bị 3 Trạm thu ảnh mây vệ tinh địa tĩnh GMS đặt tại Hà Nội, năm 1997 tiếp tục lắp đặt trạm thu ảnh vệ tinh GMS, NOAA [8].

Trong suốt thời gian từ những năm 1980 đến 2007, nguồn tư liệu ảnh viễn thám phân giải cao phục vụ công tác giám sát tài nguyên, môi trường chủ yếu là mua từ nước ngoài, theo từng dự án. Năm 2007, trạm thu ảnh vệ tinh Việt Nam được lắp đặt và vận hành, do Cục Viễn thám Quốc gia quản lý. Trạm thu nhận dữ liệu từ vệ tinh SPOT 2, SPOT 4 , SPOT 5 của Pháp và ENVISAT của Châu Âu. Việc sở hữu một trạm thu hiện đại đã đánh dấu một bước ngoặt trong cung cấp các sản phẩm ảnh viễn thám phục vụ giám sát tài nguyên thiên nhiên và môi trường, đáp ứng các nhu cầu của các Bộ, ngành, địa phương trên phạm vi cả nước. Năm 2013, trạm được nâng cấp để thu nhận ảnh vệ tinh VNREDSat-1 của Việt Nam.

Tại Viện Hàn lâm Khoa học và Công nghệ Việt Nam, tính đến thời điểm hiện nay đã có một số trạm thu ảnh vệ tinh đã và đang sử dụng hiệu quả tại các cơ quan trong Viện. Cụ thể, Viện Công nghệ Vũ trụ, Viện Vật lý đã thành công trong việc thiết kế, chế tạo và vận hành các trạm thu ảnh vệ tinh khí tượng phân giải thấp và phân giải cao các vệ tinh cực NOAA của Mỹ, vệ tinh MT-SAT của Nhật Bản và FY-2 của Trung Quốc, Terra/Aqua (ảnh MODIS) của Cơ quan vũ trụ Châu Âu (ESA) [9]:

Ngoài ra, Tổng cục Lâm nghiệp, Bộ Nông nghiệp và Phát triển nông thôn hiện cũng sở hữu trạm thu ảnh ảnh MODIS (vệ tinh Terra/Aqua) được lắp đặt từ năm 2007, phục vụ riêng cho mục đích dự báo cháy rừng.

Trong tương lai gần, nằm trong "Chiến lược nghiên cứu và ứng dụng công nghệ vũ trụ đến năm 2020" và nhu cầu phát triển trong nước, sự hội nhập quốc tế thì Việt Nam sẽ có thêm các trạm thu ảnh viễn thám sau:

Các trạm điều khiển, thu nhận dữ liệu của hai hệ thống vệ tinh radar quan sát trái đất là LOTUSat-1 và LOTUSat-2 [9] tại Hà Nội.

Trạm dự phòng cho vệ tinh LOTUSat-1 và LOTUSat-2 ở Thành phố Hồ Chí Minh [9].

Trạm thu ảnh phân giải cao vệ tinh SPOT 6, SPOT 7 của Pháp [10] tại Hà Nội.

Trạm dò tìm và thu nhận dữ liệu vệ tinh của Ấn Độ [11] tại Bình Dương.

\section{Một số nhận xét và đánh giá}

Trong khu vực Đông Nam Á, các nước có nền kinh tế phát triển đều chú trọng tới 
công nghệ vũ trụ nói chung và công nghệ viễn thám nói riêng đáp ứng nhu cầu ứng dụng trong giám sát tài nguyên thiên nhiên và môi trường. Các nước đã định hướng phát triển vệ tinh và trạm mặt đất theo cách riêng của mình và đã đạt được nhiều thành tựu, có nhiều kinh nghiệm và đã từng bước tự chủ trong công nghệ chế tạo vệ tinh, vận hành trạm mặt đất.

Các trạm mặt đất trong hệ thống vệ tinh của mỗi nước đều có chức năng thu nhận và xử lý ảnh viễn thám của các vệ tinh nước ngoài và trong nước. Mặt khác, các trạm này còn có chức năng kết nối với nhau thành một hệ thống để làm chức năng dự phòng cho điều khiển vệ tinh, thu nhận ảnh hoặc thông tin liên lạc.

Hiện nay tại Việt Nam, các trạm mặt đất vệ tinh đang hoạt động tương đối độc lập với nhau do vậy công tác quy hoạch các trạm mặt đất nói chung và các trạm thu ảnh vệ tinh nói riêng ở Việt Nam đã và đang trở nên quan trọng và cấp thiết. Công tác quy hoạch có ý nghĩa to lớn trong việc khai thác hiệu quả các nguồn tài nguyên về đất đai, tần số và đặt biệt là hiệu quả đầu tư và ý nghĩa đối với người sử dụng. $O$

\section{Tài liệu tham khảo}

[1]. Rika Andiarti, Space Activities in Indonesia. Report on Asia-Pacific Regional Space Agency Forum (APRSAF-22), 2015.

[2]. Toto Marnanto Kadri, Indonesian LAPAN-TUBSAT Micro-Satellite Development, Report on Asia-Pacific Regional Space Agency Forum (APRSAF14), 2007.

[3]. Bambang, Indonesia Country report, Report on Asia-Pacific Regional Space
Agency Forum (APRSAF-20), 2013.

[4]. Thongchai Charuppat, THAILAND's Activities Contributing to GEOSS Implementation, GISTDA, Thailand.

[5]. GISTDA profile, www.gistda.org.th, 2016.

[6]. Abdul Kadir Taib, Applications of EOS Data for National Development in Malaysia, Geospatial World Forum, 2012.

[7]. Azman Ahmad, The utilization of remote sensing and G/S technology in various application for substainable development in Malaysia, ESA Symposium "Space Tools and solutions Monitoring the Atmosphere and Land cover", Austria, 2008.

[8]. "Chiến lược nghiên cứu và ứng dụng công nghệ vũ trụ đến năm 2020", Ban hành kèm theo Quyết định số 137/2006/QĐ-TTg của Thủ tướng Chính phủ.

[9]. Bùi Trọng Tuyên, "Tổng quan các trạm thu ảnh vệ tinh của Viện Hàn lâm Khoa học và Công nghệ Việt Nam hiện tại và dự kiến triển khai đến năm 2020 ở Việt Nam. Đề tài "Nghiên cứu cơ sở khoa học phục vụ quy hoạch mạng lưới trạm thu ảnh viễn thám, 2016

[10]. Quyết định số 966/QĐ-BTNMT ngày 28/4/2016 của Bộ Tài nguyên và Môi trường về việc phê duyệt dự toán chuẩn bị đầu tư Hợp phần 1 Dự án "Chống chịu khí hậu tổng hợp và sinh kế bền vững Đồng bằng song Cửu Long.

[11]. RF Noise survey report, Indian Asean Space project, Indian Space Research Organisation, 2015.O 